\title{
The Original Freeze-Substitution Device
}

\author{
Alexander S. Kaprelyants*, Regina K. Migunova \\ Independent Association for Researchers Electron Microscopist, 32 Mironositskya St, \#14 \\ Kharkov, 61002, Ukraine *E-mail: kaprelyants@yahoo.com
}

The original device that implements freeze-substitution method [1] is made of the desk apparatus, comprising cryogenic and electronic parts (Fig. 1A.). Cryochamber (Fig. 1B.) contains cylindrical unit (1), central channel (2) and located around it cylindrical vessels (3), connected by means of upper (4) and lower (5) channels with the central one. Perforated containers (6) with frozen specimen are adjusted on metal rack (7). The flux inducer (8) provides the circulation of substituting medium. The cold-conduct (9) is submerged into liquid nitrogen. Temperature control is performed be the thermo gauge (10). The range of operating temperatures stabilization is from $+20^{\circ} \mathrm{C}$ to $-120^{\circ} \mathrm{C}$.

The principle of the device work consist in the fact that in the central channel there is the circulation of ice-substituting medium between central channel where it is cooled by the cold-conductor surface, and vessels with containers by upper and lower channels. Ukrainian Patent pending.

This device was used for cryobiological research studies. In our experiments we used different frozen tissue placed into the cryochamber for substitution at $-80^{\circ} \mathrm{C}$. The substitution medium was acetone-glutaraldehyde-uranylacetate mixture. After substitution samples underwent electron microscopy examination to evaluate ultrastructure integrity and presence or absence of ice crystals. The substitution time and the thickness of the tissue were optimized.

Understanding the mechanism of ice crystal formation in cell and tissue has an important value for the development of new methods in cryobiology and cryomedicine. This freeze-substitution device was used for cooling effect investigation on rats liver tissue for ice crystal visualization. We studied of the localization, intracellular redistribution and morphological characteristics of ice crystals in frozen tissue. During electron microscopy analysis the sites of the ice crystal localization in liver cells were found as light cavities of different shape and sizes (Fig. 2). Performed digital morphometrical analysis allowed to determinate average values of ice crystal square and shape-factors. We have the opportunity to evaluate of cellular ultrastructure changes at frozen state also.

\section{References}

[1] J.J. Bozzola et al., Electron Microscopy Principles and Techniques for Biologist, $2^{\text {nd }}$ ed., Jones and Bartlett Publishers, Boston, Toronto, London, Singapore, 1999. 

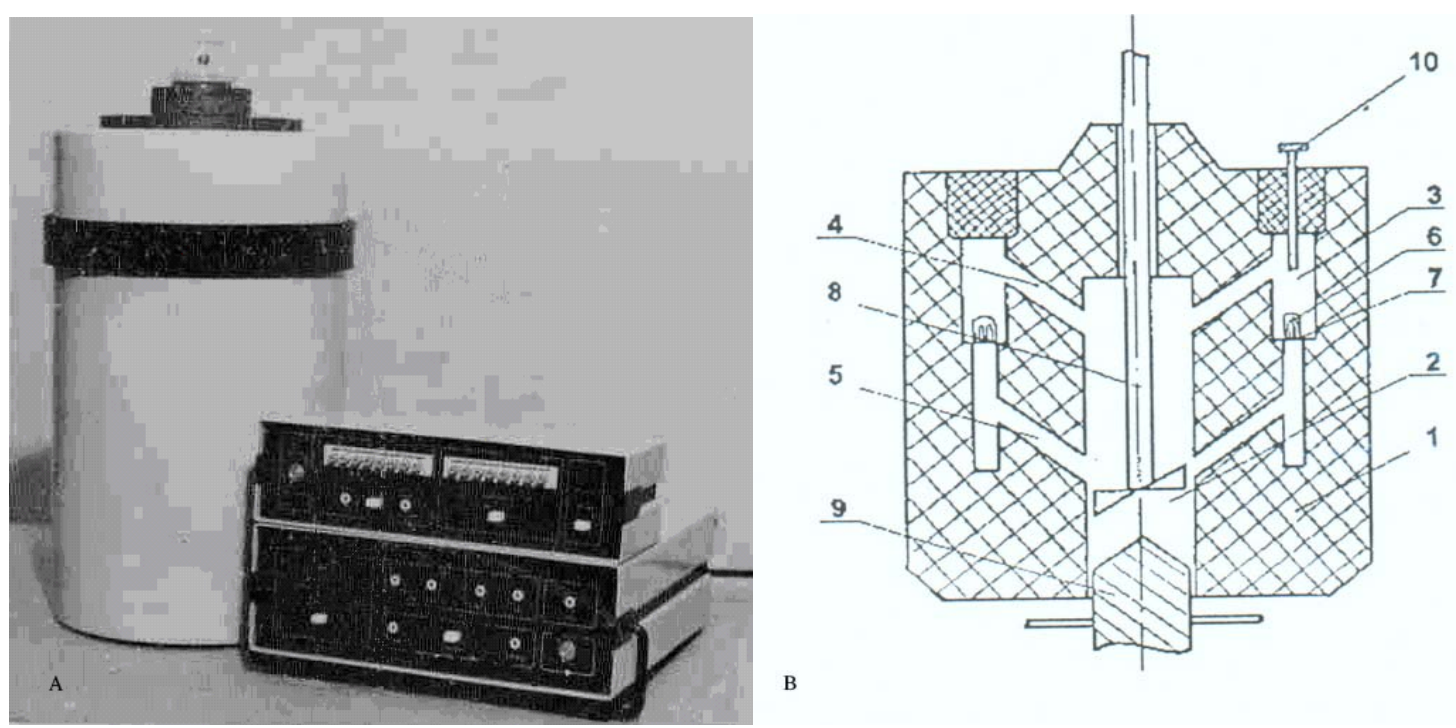

Fig. 1. The freeze-substitution device. A. The general view. B. The cryobamber scheme.

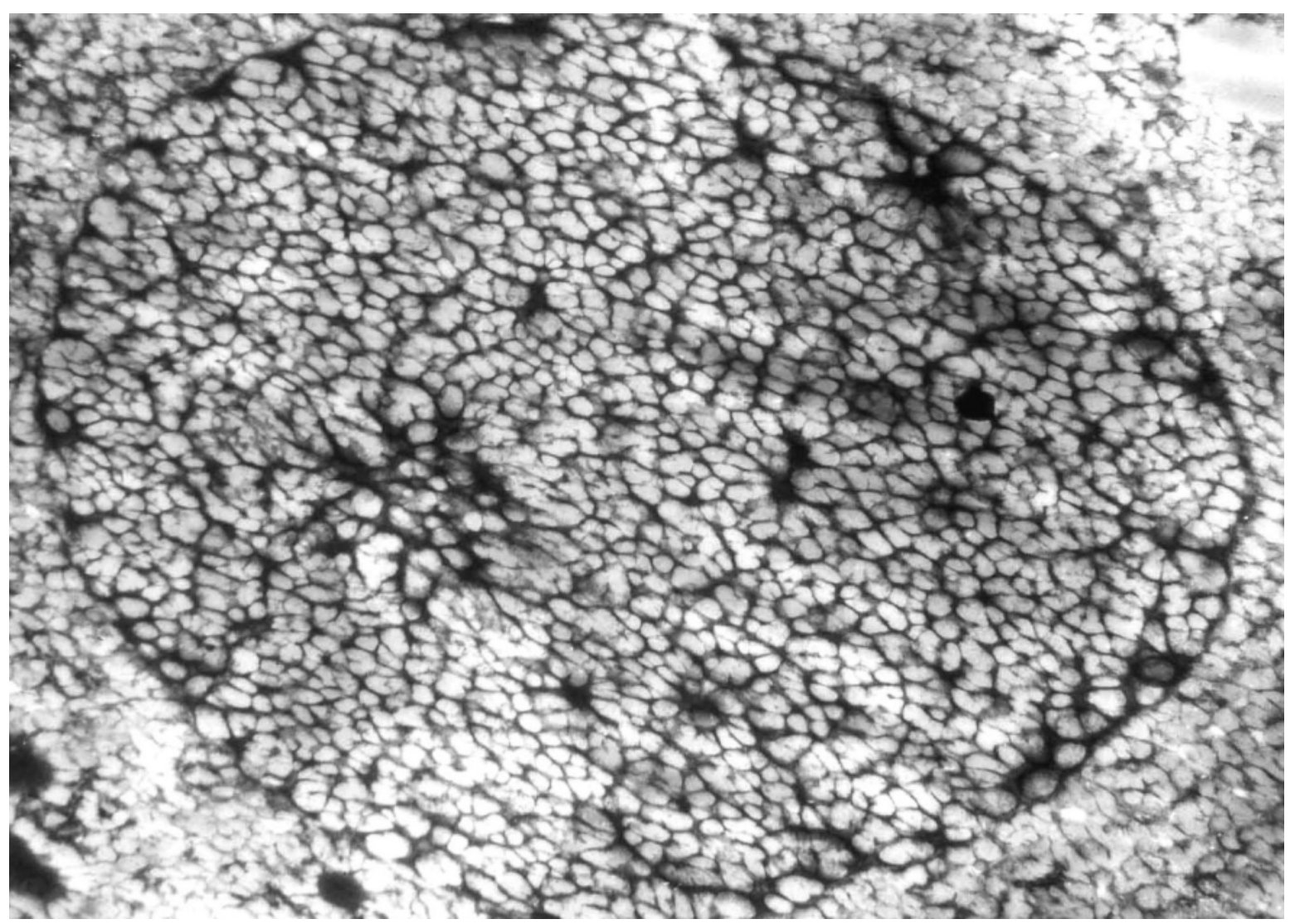

Fig. 2. Ice crystals visualization as light cavities in frozen rats liver tissue. Intanuclear small ice crystal formation $\left(-180^{\circ} \mathrm{C}\right)$. 